\title{
Pneumonia and central nervous system infection caused by reactivation of varicella-zoster virus in a living-donor kidney transplantation patient: case report and review of the literature
}

\author{
Yoshinori Takahashi ${ }^{1} @$ - Satoshi Hara ${ }^{1} \cdot$ Ryohei Hoshiba $^{1} \cdot$ Shinya Hibino ${ }^{1} \cdot$ Kiyoaki Ito $^{1} \cdot$ Takeshi Zoshima $^{1}$. \\ Yasunori Suzuki ${ }^{1} \cdot$ Dai Inoue $^{2} \cdot$ Ichiro Mizushima $^{1} \cdot$ Hiroshi Fujii $^{1} \cdot$ Mitsuhiro Kawano $^{1}$
}

Received: 5 October 2020 / Accepted: 6 January 2021 / Published online: 27 January 2021

(c) Japanese Society of Nephrology 2021

\begin{abstract}
Varicella-zoster virus (VZV) typically causes herpes zoster in the elderly due to reactivation, but immunocompromised individuals may develop organ damage such as pneumonia with a poor prognosis. We herein report a case of pneumonia and central nervous system (CNS) infection caused by reactivation of VZV in a 50-year-old man who had received a livingdonor kidney transplant. We also conducted a literature review of adult cases with pneumonia or CNS infection caused by VZV after kidney transplantation. It showed that there are cases in which eruptions appeared upto 21 days after the onset of the disease and others in which eruptions did not appear at any time during the clinical course. Furthermore, there may be a wide variety of intervals from kidney transplantation to VZV infection (including both primary infection and reactivation of VZV), ranging from 2 weeks to 11 years. Therefore, it should be kept in mind that kidney transplant patients are always at high risk of VZV infection, as early recognition and treatment of the disease improves its prognosis. Although the diagnosis of varicella pneumonia is generally made by PCR test of bronchoalveolar lavage fluid, our case experience suggests that the less invasive PCR test of sputum may be useful for rapid and accurate diagnosis. The efficacy of inactivated recombinant zoster vaccine in immunocompromised individuals at high risk of reactivation of VZV also needs to be examined in the future.
\end{abstract}

Keywords Varicella-zoster virus $\cdot$ Kidney transplantation $\cdot$ Varicella pneumonia $\cdot$ VZV meningitis

\section{Introduction}

Varicella, which often occurs in childhood, is characterized by an acute febrile vesicular rash with a favorable prognosis due to primary infection with varicella-zoster virus (VZV).

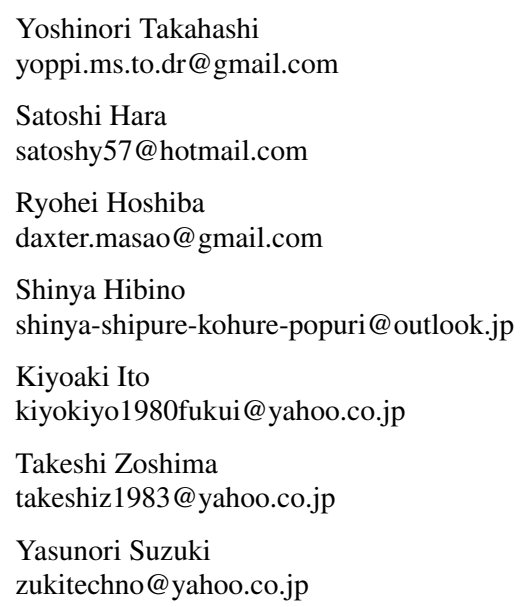

Latent infection of VZV occurs in sensory nerve ganglia, and reactivation in elderly persons causes herpes zoster in the innervated area [1]. Early diagnosis and swift treatment are important for primary infection of adults or reactivation in an immunocompromised host because they are more

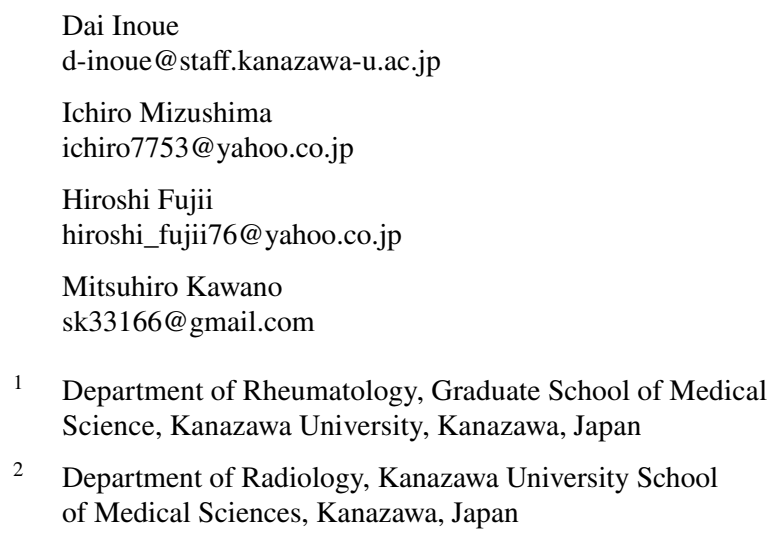


likely to be associated with organ lesions such as pneumonia and central nervous system (CNS) infection, associated with a poorer prognosis [1]. However, several cases of VZV infection in immunocompromised hosts with a fatal outcome due to a delayed diagnosis because of the lack of typical vesicular eruptions at onset have been reported [2-4]. We experienced a living-donor kidney transplantation patient who had varicella pneumonia, meningitis and multiple cranial nerve palsy due to reactivation of VZV. Polymerase chain reaction (PCR) of sputum supported the diagnosis of varicella pneumonia, and administration of acyclovir and glucocorticoid led to an almost complete recovery. In this case, early diagnosis was difficult because diverse symptoms/signs appeared prior to the typical skin eruption. In this report, we also conducted a literature review of kidney transplant patients who developed pneumonia or CNS infection caused by VZV, and divided them according to whether the eruption preceded or followed the organ lesions, and then compared them to identify any significant differences in their clinical features and outcome.

\section{Case report}

A 50-year-old man, who had undergone living-donor kidney transplantation for autosomal dominant polycystic kidney disease 2 years previously, was admitted to our hospital because of fever, wet cough, dyspnea, vesicles on the right external ear and diplopia. Renal function had been stable with immunosuppressive therapy including prednisolone $5 \mathrm{mg} /$ day, tacrolimus $1.5 \mathrm{mg} /$ day (serum trough level $5.5 \mathrm{ng} /$ $\mathrm{mL}$ ), and mycophenolate mofetil $1000 \mathrm{mg} /$ day. He had been taking trimethoprim-sulfamethoxazole for the prevention of pneumocystis pneumonia. Eleven days prior to admission, fever and headache were noted, followed by right neck pain and earache. Five days before admission, wet cough, and dyspnea developed but chest computed tomography (CT) (3 days before admission) revealed only very small groundglass opacities in the middle lobe of the right lung with mild bronchial wall thickening. Levofloxacin was initiated, but the symptoms tended rather to deteriorate. On the day of hospitalization, vesicles of the right external ear and diplopia appeared simultaneously. The diagnosis of VZV infection was made by Tzanck test of vesicles and VZV antigen test by immunochromatography.

On admission, body temperature was $38.6^{\circ} \mathrm{C}$, blood pressure $111 / 88 \mathrm{mmHg}$, pulse rate $96 / \mathrm{min}$, respiratory rate $12 /$ min, $\mathrm{SpO}_{2} 91 \%$ on room air, and consciousness clear. Physical examination showed no nuchal rigidity. Rhonchi were heard over the bilateral chest wall, and several vesicles were found around the right external ear. Neurological findings were remarkable for an abduction disorder in the right eye, right curtain sign, but there was no facial palsy indicating
Ramsay-Hunt syndrome. Right recurrent nerve palsy and dysphagia were also observed by laryngoscopy and swallowing videofluorography, respectively. Laboratory findings on admission are shown in Table 1. Mild leukocytosis with elevated C-reactive protein was remarkable. $\beta$-D glucan, cytomegalovirus antigen, and VZV-IgM (by enzyme immunoassay: EIA) were all negative but VZV-IgG was positive (Table 1). On admission, intravenous acyclovir administration (500 mg q12h) was initiated for VZV infection in

Table 1 Laboratory data of the present case on admission to our hospital

\begin{tabular}{|c|c|c|}
\hline & Value & Normal range \\
\hline \multicolumn{3}{|l|}{ Blood count } \\
\hline White blood cells $(/ \mu \mathrm{L})$ & 11,800 & $3300-8800$ \\
\hline Neutrophil (\%) & 89 & $48-72$ \\
\hline Lymphocyte (\%) & 7.5 & $20-42$ \\
\hline $\mathrm{RBC} \times 10^{4}(/ \mu \mathrm{L})$ & 508 & $430-550$ \\
\hline $\mathrm{Hb}(\mathrm{g} / \mathrm{dL})$ & 15.0 & $13.5-17.0$ \\
\hline $\mathrm{Ht}(\%)$ & 43.1 & $39.7-51.0$ \\
\hline $\mathrm{Plt} \times 10^{4}(/ \mu \mathrm{L})$ & 13.7 & $13.0-35.0$ \\
\hline \multicolumn{3}{|l|}{ Serum chemistry } \\
\hline BUN (mg/dL) & 24 & $8-22$ \\
\hline $\mathrm{Cr}(\mathrm{mg} / \mathrm{dL})$ & 1.56 & $0.60-1.00$ \\
\hline $\mathrm{eGFR}\left(\mathrm{mL} / \mathrm{min} / 1.73 \mathrm{~m}^{2}\right)$ & 38.8 & $\geq 60$ \\
\hline $\mathrm{UA}(\mathrm{mg} / \mathrm{dL})$ & 5.1 & $3.6-7.0$ \\
\hline $\mathrm{Na}(\mathrm{mEq} / \mathrm{L})$ & 129 & $135-149$ \\
\hline $\mathrm{K}(\mathrm{mEq} / \mathrm{L})$ & 3.9 & $3.5-4.9$ \\
\hline $\mathrm{Cl}(\mathrm{mEq} / \mathrm{L})$ & 93 & $96-108$ \\
\hline ALP (IU/L) & 137 & $115-359$ \\
\hline$\gamma$-GTP (IU/L) & 17 & $10-47$ \\
\hline AST (IU/L) & 13 & $13-33$ \\
\hline ALT (IU/L) & 8 & $8-42$ \\
\hline LDH (IU/L) & 176 & $119-229$ \\
\hline T-Bil (IU/L) & 1.4 & $0.3-1.2$ \\
\hline $\mathrm{TP}(\mathrm{g} / \mathrm{dL})$ & 6.1 & $6.7-8.3$ \\
\hline Alb (g/dL) & 3.8 & $4.0-5.0$ \\
\hline Plasma glucose (mg/dL) & 111 & 69-109 \\
\hline HbA1c (\%) & 6.2 & $4.3-5.8$ \\
\hline CRP (mg/dL) & 4.6 & $0.0-0.3$ \\
\hline $\operatorname{IgG}(\mathrm{mg} / \mathrm{dL})$ & 752 & $870-1700$ \\
\hline \multicolumn{3}{|l|}{ Infectious findings } \\
\hline VZV-IgM (EIA) & 0.39 & $<0.8$ \\
\hline VZV-IgG (EIA) & 45.3 & $<2.0$ \\
\hline$\beta$-D glucan $(\mathrm{pg} / \mathrm{mL})$ & $<6.0$ & $<6.0$ \\
\hline CMV antigen & Negative & Negative \\
\hline Urinary Legionella antigen & Negative & Negative \\
\hline SARS-CoV-2 RT-PCR & Negative & Negative \\
\hline \multicolumn{3}{|l|}{ Culture findings } \\
\hline Blood & Negative & Negative \\
\hline Sputum & Normal flora & Negative \\
\hline
\end{tabular}


Fig. 1 Chest CT performed on 2nd hospital day showed bilateral ground glass opacities and bronchial wall thickening along the bronchi

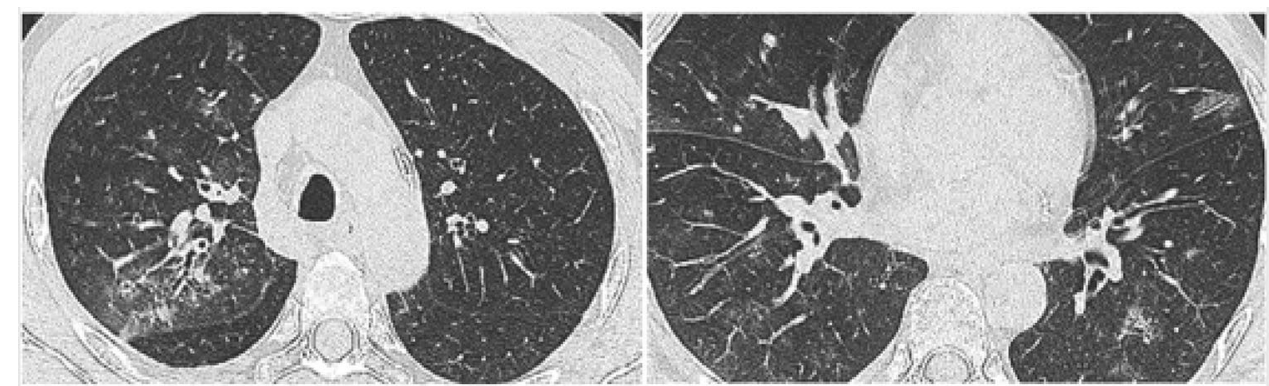

Table 2 Laboratory data of cerebral spinal fluid on 11th hospital day

\begin{tabular}{lll}
\hline & Value & Normal range \\
\hline Appearance & Colorless, transparent & \\
Opening pressure $\left(\mathrm{mmH}_{2} \mathrm{O}\right)$ & 170 & $50-180$ \\
Cell number $(/ \mu \mathrm{L})$ & 280 & $<5$ \\
Mononuclear cell $(\%)$ & 99.6 & \\
Polynuclear cell $(\%)$ & 0.4 & \\
Protein $(\mathrm{mg} / \mathrm{dL})$ & 173 & $10-40$ \\
Sugar $(\mathrm{mg} / \mathrm{dL})$ & 65 & $40-75$ \\
Plasma glucose $(\mathrm{mg} / \mathrm{dL})$ & 113 & $69-109$ \\
CSF sugar/Plasma glucose & 0.57 & $>0.6$ \\
ratio & & \\
Culture & Negative & Negative \\
VZV-IgG $($ EIA) & $>12.8$ & $<0.20$ \\
VZV-DNA $($ copies/mL) & $<2.0 \times 10^{2}$ & $<2.0 \times 10^{2}$ \\
\hline
\end{tabular}

addition to meropenem and levofloxacin for pneumonia, and the dose of mycophenolate mofetil was reduced to $500 \mathrm{mg} /$ day. Two days after admission, chest CT was performed again and revealed bilateral multiple patchy ground-glass opacities along the bronchi and mild bronchial wall thickening, indicating atypical pneumonia (Fig. 1). Therefore, varicella pneumonia was suspected and he was isolated in a negative pressure room to prevent airborne infection. While sputum culture showed no pathogenic bacterial growth, a PCR assay for sputum showed a positive VZV-DNA quantification of $5.0 \times 10^{5}$ copies $/ \mathrm{mL}$. Since it was confirmed that serum VZV-IgG was positive when renal transplantation was performed, the diagnosis of varicella pneumonia due to reactivation of VZV was made. Eleven days after admission, cerebrospinal fluid (CSF) test revealed pleocytosis with dominant mononuclear cells (WBC $280 / \mu \mathrm{L}$, mononuclear cell 99.6\%) with elevated protein level $(173 \mathrm{mg} / \mathrm{dL})$. Although VZV-DNA in the CSF was negative, VZV-IgG in the CSF was elevated over 12.8 by EIA (Table 2). Brain magnetic resonance imaging (MRI) on the 31st hospital day showed low signal nodular lesions on $\mathrm{T} 2 *$ weighted images of the brainstem and left parietal lobe surface, consistent with the site of symptoms (Fig. 2). The distribution of these lesions was atypical for a subclinical lacunar hemorrhage, particularly that associated with atherosclerosis, and there was no evidence of aneurysm, encephalitis or cerebral infarction, which suggested a diagnosis of VZV meningitis and might be related to VZV vasculopathy in conjunction with the CSF findings. Methylprednisolone $(1 \mathrm{mg} / \mathrm{kg} /$ day) was added on the 4th hospital day for severe pneumonia because of a temporary increase in oxygen demand. Thereafter, the respiratory symptoms gradually improved by the 7 th hospital day
Fig. $2 \mathrm{~T} 2 *$ weighted image of brain MRI performed on 31 st hospital day. There were low-intensity areas on the left frontal subcortex and the left side of the pons-medullary level brainstem, which suggested post-bleeding change (yellow arrows)

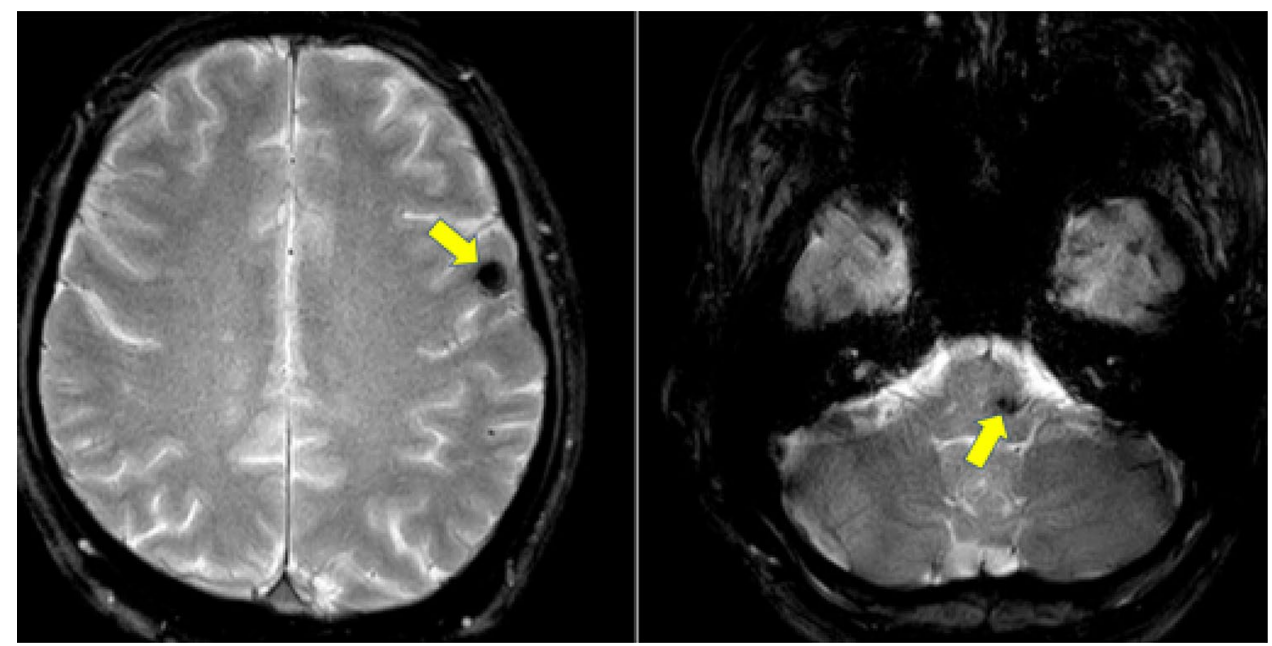


and the dose of corticosteroids was gradually returned to the maintenance dose. The amount of VZV-DNA in sputum also gradually declined, and intravenous acyclovir administration was stopped on the 30th hospital day. However, improvement of the abducens nerve palsy and dysphagia was very slow, and inflammatory findings in the CSF persisted. So, additional therapy including methylprednisolone pulse therapy and oral valacyclovir administration was given on the 40th and 52nd hospital day respectively, which led to improvement of his symptoms and CSF inflammatory findings. He was discharged on the 93rd hospital day without deterioration of renal function (Fig. 3).

\section{Discussion}

We experienced a case of VZV infection in a living-donor kidney transplant patient, in which multi-organ involvement affecting lungs, meninges, cerebral blood vessels, and cranial nerves was noted. This case was characterized by the onset of the disease 11 days before the appearance of typical vesicles due to VZV infection, which hampered the early diagnosis. Since serum anti-VZV IgG antibodies were positive 2 years before admission, reactivation of VZV was considered to be the cause in this case. We searched the literature through MEDLINE/Pubmed from January 2000 to January 2020, using the following terms: ["renal transplantation" OR "kidney transplantation"] AND "varicella-zoster virus", and case reports of adults with pneumonia or CNS infections. This review was divided according to the timing of the appearance of skin eruptions, i.e., cases in which eruption preceded or simultaneously appeared with organ lesions [5-12] (Table 3), and those in which no eruption was noted when symptoms started [2-4, 7, 11-16] (Table 4). We excluded case reports with insufficient clinical information.
VZV infection is preceded by pain and/or organ lesions, and in some cases eruptions may not appear. Pain at the involved site precedes the eruptions in $75 \%$ of herpes zoster [17]. It typically takes 2-3 days for a skin eruption to appear, but in some reports it was weeks [18]. There is also a subtype of herpes zoster called "zoster sine herpete" in which no skin rash appears [1]. Our literature review showed that there are cases in which eruptions appeared 2-21 days after the onset of the disease and those in which eruptions did not appear at any time during the clinical course [2-4, 7, 11-16] (Table 4). In addition, there may be a wide variety of intervals from kidney transplantation to VZV infection, ranging from 2 weeks to 11 years [2-16] (Tables 3, 4). In our case, early recognition of VZV infection was difficult because there was an 11-day interval between the onset of symptoms and appearance of typical vesicular rashes and he showed a very stable clinical course for 2 years after kidney transplantation.

The usefulness of PCR test in the diagnosis of varicella pneumonia has recently been documented. Varicella pneumonia often occurs in adults with initial VZV infection, but rarely in those with VZV reactivation, which can be fatal in solid organ transplant patients [14].Early diagnosis and starting treatment without delay are important because the mortality rate is as high as 10-33\% [19]. Real-time PCR test using bronchoalveolar lavage fluid (BALF) is reported to be useful for the early diagnosis of varicella pneumonia [20], and its sensitivity is higher than that of virus culture test [21, 22]. While almost all reported cases of varicella pneumonia in which the infection of the virus in the respiratory tract was confirmed were proved by PCR test of BALF, a few cases have been diagnosed by the PCR test using sputum like the present case [23]. Since the sputum PCR test is less invasive than bronchoscopy, further cases using the sputum PCR test are expected to be accumulated.
Fig. 3 Clinical course in our case. The eruption had been preceded by fever and cough for several days. Symptoms improved with acyclovir and methylprednisolone pulse therapy, and VZV-DNA in sputum and cerebrospinal fluid cell counts decreased as well. $M E P M$ meropenem, $L V F X$ levofloxacin, $A C V$ acyclovir, $V A C V$ valacyclovir, $P S L$ prednisolone, mPSL methylprednisolone, $V Z V$ varicella-zoster virus, $C S F$ cerebrospinal fluid, $W B C$ white blood cell, $C T$ computed tomography, MRI magnetic resonance imaging

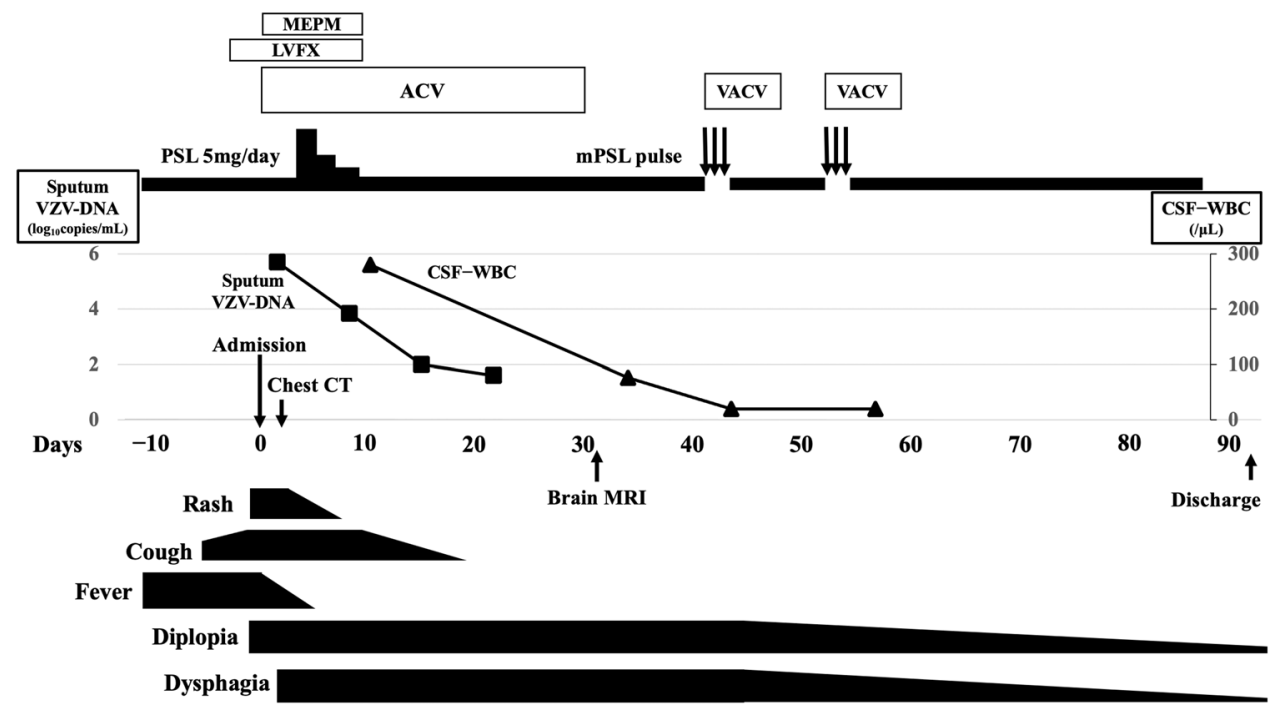




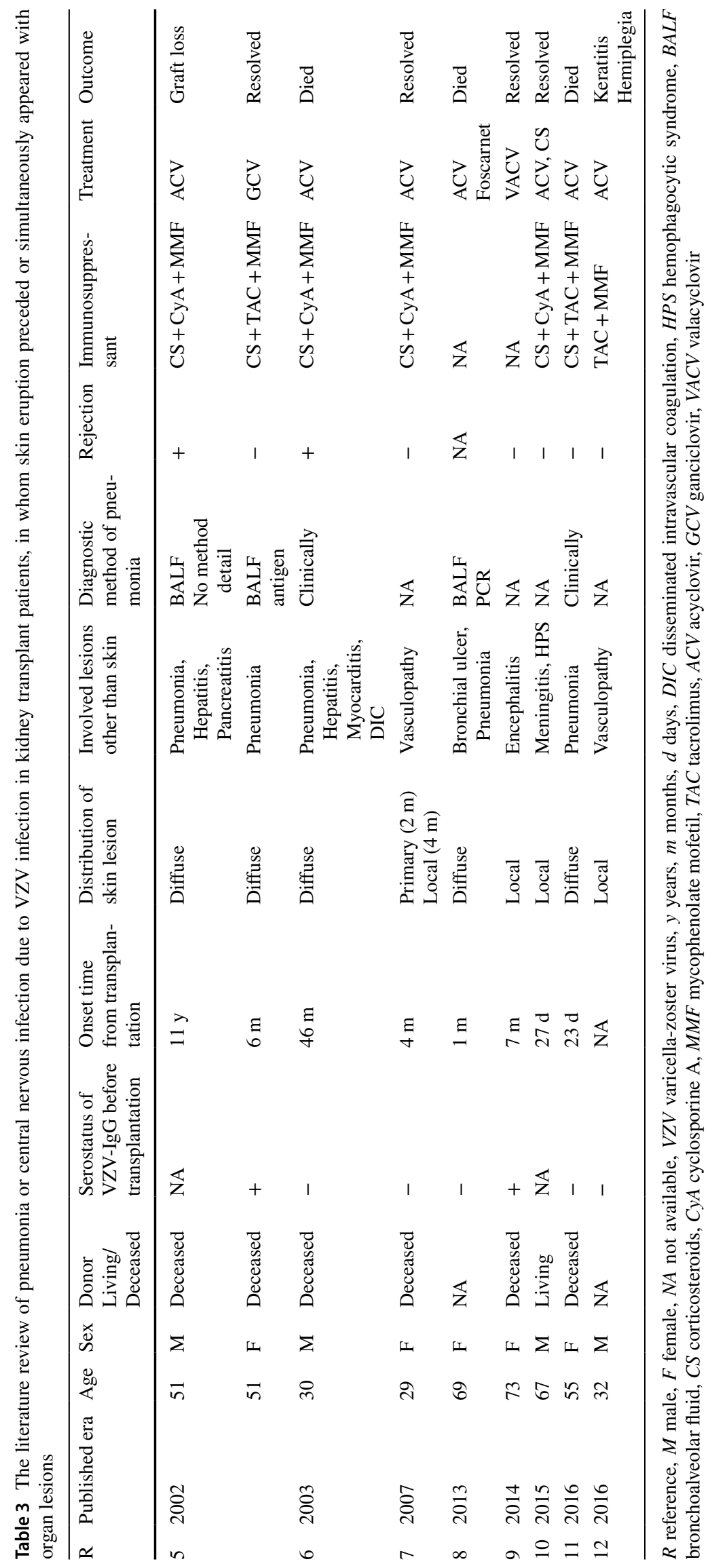




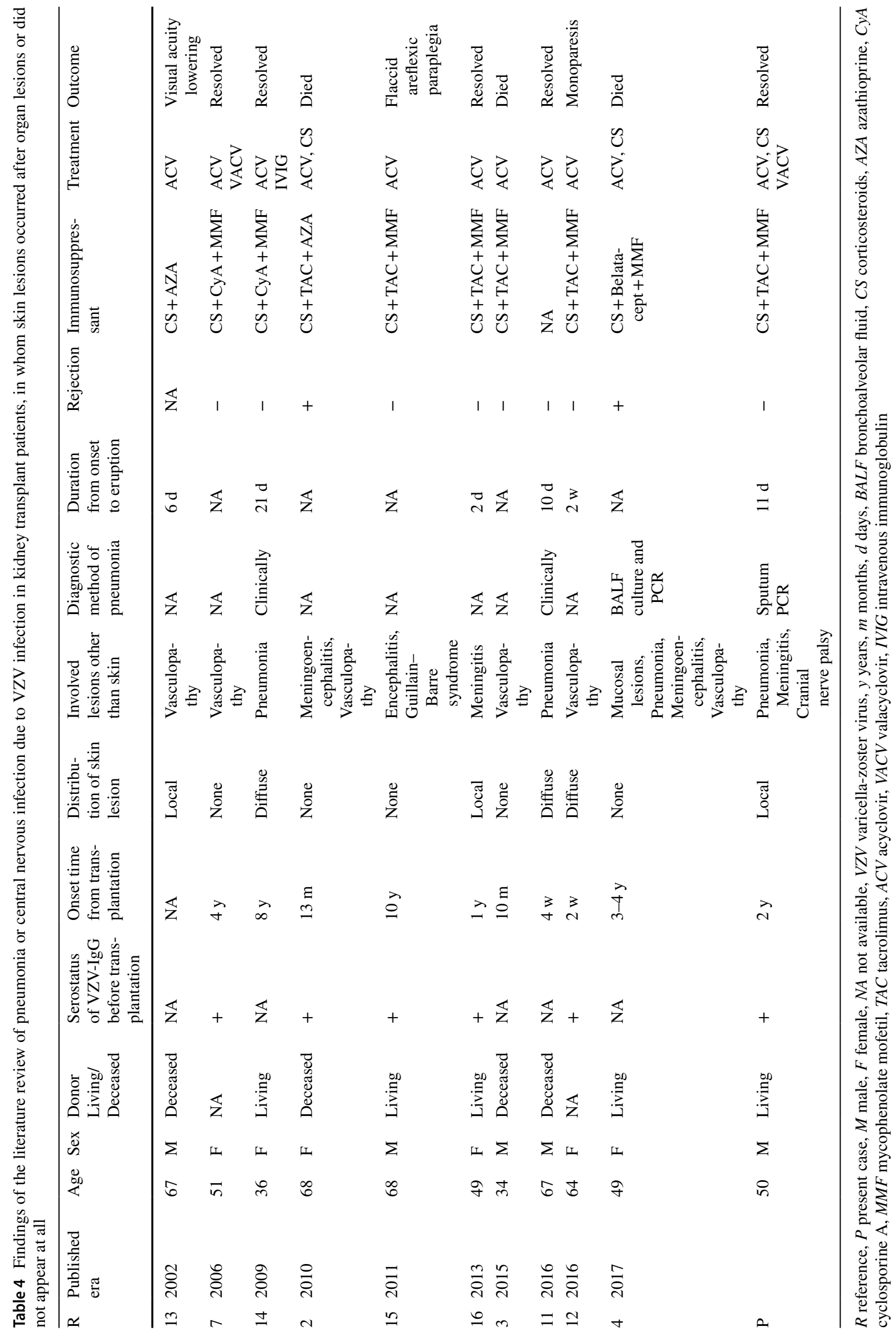


It may be effective to add corticosteroids to the standard treatment, acyclovir, for CNS infections caused by VZV infection. VZV causes various types of central nervous system infection, aseptic meningitis, encephalitis, cerebellitis, myelitis, cranial nerve palsy such as Ramsay-Hunt syndrome and vasculopathy [24]. VZV affects any size of blood vessel and induces vasculopathy, which frequently causes infarcted lesions at the border between white matter and gray matter, and occasionally is associated with hemorrhagic lesions [24-26]. While it has been reported that initiating acyclovir as early as possible at the onset improves the prognosis, some experts recommend the addition of corticosteroids for vasculopathy and Ramsay Hunt syndrome [24-27]. In our literature review, it was unclear whether the addition of corticosteroids was more effective or not because corticosteroids are rarely used for CNS infections in kidney transplant patients [2-16] (Tables 3, 4). In the present case, symptoms tended to improve with the initiation of corticosteroids, suggesting that their addition may be beneficial for VZV meningitis and cranial nerve palsy. However, this will have to be validated by accumulating more cases in the future.

Recently, it has been expected that an inactivated vaccine, recombinant zoster vaccine (RZV), may be effective for preventing herpes zoster due to reactivation of VZV in the immunocompromised host. The preventive effect of RZV on herpes zoster and postherpetic neuralgia is high at $90 \%$ or more in older adults ( $\geq 50$ years) [28], and is prolonged [29]. It was approved also in Japan in 2018 for the prevention of herpes zoster in persons over the age of 50 years. It can be used in immunocompromised hosts because of its inactivated nature. In a group undergoing autologous hematopoietic stem cell transplantation, RZV vaccination reduced the incidence of herpes zoster by $68 \%$ after transplantation [30]. It has been reported that immunogenicity and safety were assured by RZV vaccination in patients after kidney transplantation with low rejection risk [31]. Based on these results, the American society of transplantation guidelines recommend that RZV vaccination can be considered not only before but also after kidney transplantation with a low risk of rejection [32]. Although RZV vaccination is now approved only in those 50 years or older, the efficacy of RZV in young immunocompromised hosts should also be investigated in future studies because young patients with kidney transplant are also at risk for reactivation of VZV.

We experienced a case of pneumonia, meningitis and multiple cranial nerve palsy due to VZV reactivation after living-donor kidney transplantation. In this case, organ lesions preceded the typical vesicular rashes resulting in a delay in the initiation of antiviral treatment. Noninvasive sputum PCR test instead of bronchoscopy seemed to be useful for the rapid and accurate diagnosis of varicella pneumonia. Our case suggests that in cases with atypical pneumonia, sputum PCR test for VZV might be useful even if typical vesicular rashes of VZV are absent. In the future, it will be necessary to further evaluate the effectiveness of RZV to prevent reactivation of VZV in kidney transplant patients of all ages.

\section{Compliance with ethical standards}

Conflict of interest None of the authors have any competing interests to declare.

Human and animal rights This article does not contain any studies with human participants or animals performed by any of the authors.

Informed consent Written informed consent was obtained from the patient for publication of this case, report and accompanying images.

\section{References}

1. Cohen JI. Clinical practice: Herpes Zoster. N Engl J Med. 2013;369:255-63.

2. Jantsch J, Schmidt B, Bardutzky J, et al. Lethal varicella-zoster virus reactivation without skin lesions following renal transplantation. Nephrol Dial Transplant. 2011;26:365-8.

3. Sampathkumar K, Prabhakar A, Vijay AC. Quiz page April 2015: fever and encephalopathy in a kidney transplant recipient. Am J Kidney Dis. 2015;65:A18-21.

4. Helou E, Grant M, Landry M, et al. Fatal case of cutaneoussparing orolaryngeal zoster in a renal transplant recipient. Transpl Infect Dis. 2017;19.

5. Fehr T, Bossart W, Wahl C, et al. Disseminated varicella infection in adult renal allograft recipients: four cases and a review of the literature. Transplantation. 2002;73:608-11.

6. Lauzurica R, Bayés B, Frías C, et al. Disseminated varicella infection in adult renal allograft recipients: role of mycophenolate mofetil. Transplant Proc. 2003;35:1758-9.

7. Hovens MM, Vaessen N, Sijpkens YW, et al. Unusual presentation of central nervous system manifestations of Varicella zoster virus vasculopathy in renal transplant recipients. Transpl Infect Dis. 2007;9:237-40.

8. Inokuchi $\mathrm{R}$, Nakamura $\mathrm{K}$, Sato $\mathrm{H}$, et al. Bronchial ulceration as a prognostic indicator for varicella pneumonia: case report and systematic literature review. J Clin Virol. 2013;56:360-4.

9. Nabi S, Kahlon P, Goggins M, et al. VZV encephalitis following successful treatment of CMV infection in a patient with kidney transplant. BMJ Case Rep. 2014;2014:bcr2014206655.

10. Nanmoku K, Yamamoto T, Tsujita M, et al. Virus-associated hemophagocytic syndrome in renal transplant recipients: report of 2 cases from a single center. Case Rep Hematol. 2015;2015:876301.

11. Depledge DP, Brown J, Macanovic J, et al. Viral genome sequencing proves nosocomial transmission of fatal varicella. $\mathrm{J}$ Infect Dis. 2016;214:1399-402.

12. Renoult E, Lanthier S, Rouleau D, et al. Varicella Zoster virus vasculopathy after kidney transplantation. Transplantation. 2016;100:e19-20.

13. Ostermann ME, Gyawali P, Snowden SA, et al. A 67-year-old kidney transplant patient with headache of uncertain origin. Nephrol Dial Transplant. 2002;17:508-10. 
14. Sato A, Amada N, Kikuchi H, et al. Pneumonia due to varicellazoster virus reinfection in a renal transplant recipient. Transplant Proc. 2009;41:3959-61.

15. Assi M, Abou AS. Unusual neurologic manifestations of varicella zoster virus infection with the absence of rash in a kidney transplant recipient. Transpl Infect Dis. 2011;13:545-7.

16. Rau $S$, von Baumgarten $L$, Habicht $A$, et al. Headaches after renal transplantation-a case report. Transplant Proc. 2013;45:2795-7.

17. Dworkin RH, Johnson RW, Breuer J, et al. Recommendations for the management of herpes zoster. Clin Infect Dis. 2007;44(Suppl 1):S1-26.

18. Kost RG, Straus SE. Postherpetic neuralgia-pathogenesis, treatment, and prevention. N Engl J Med. 1996;335:32-42.

19. Centers for Disease Control and Prevention (CDC). Varicellarelated deaths among adults-United States, 1997. MMWR Morb Mortal Wkly Rep. 1997;46:409-12.

20. Mohsen AH, McKendrick M. Varicella pneumonia in adults. Eur Respir J. 2003;21:886-91.

21. Schmutzhard J, Merete Riedel H, Zweygberg Wirgart B, et al. Detection of herpes simplex virus type 1 , herpes simplex virus type 2 and varicella-zoster virus in skin lesions. Comparison of real-time PCR, nested PCR and virus isolation. J Clin Virol. 2004;29:120-6.

22. Harbecke R, Oxman MN, Arnold BA, et al. A real-time PCR assay to identify and discriminate among wild-type and vaccine strains of varicella-zoster virus and herpes simplex virus in clinical specimens, and comparison with the clinical diagnoses. J Med Virol. 2009;81:1310-22.

23. Muramatsu H, Kuriyama A, Anzai Y, et al. A co-infection of varicella-zoster virus and Pneumocystis jirovecii in a non-HIV immunocompromised patient: a case report. BMC Infect Dis. 2019;19:1092.

24. Grahn A, Studahl M. Varicella-zoster virus infections of the central nervous system-Prognosis, diagnostics and treatment. J Infect. 2015;71:281-93.
25. Nagel MA, Bubak AN. Varicella Zoster virus vasculopathy. J Infect Dis. 2018;218(suppl_2):S107-12.

26. Gilden D, Cohrs RJ, Mahalingam R, et al. Varicella zoster virus vasculopathies: diverse clinical manifestations, laboratory features, pathogenesis, and treatment. Lancet Neurol. 2009;8:731-40.

27. Kinishi M, Amatsu M, Mohri M, et al. Acyclovir improves recovery rate of facial nerve palsy in Ramsay Hunt syndrome. Auris Nasus Larynx. 2001;28:223-6.

28. Lal H, Cunningham AL, Godeaux O, et al. Efficacy of an adjuvanted herpes zoster subunit vaccine in older adults. N Engl J Med. 2015;372:2087-96.

29. Dooling KL, Guo A, Patel M, et al. Recommendations of the advisory committee on immunization practices for use of herpes zoster vaccines. MMWR Morb Mortal Wkly Rep. 2018;67:103-8.

30. Bastidas A, de la Serna J, El Idrissi M, et al. Effect of recombinant zoster vaccine on incidence of herpes zoster after autologous stem cell transplantation: a randomized clinical trial. JAMA. 2019;322:123-33.

31. Vink P, the Zoster-028 Study Group. Immunogenicity and safety of a candidate subunit adjuvanted herpes zoster vaccine in adults with solid tumors vaccinated before or during immunosuppressive chemotherapy treatment: a phase II/III, randomized clinical trial. Open Forum Infect Dis. 2017;4(Suppl_1):S417-8.

32. Pergam SA, Limaye AP, AST Infectious Diseases Community of Practice. Varicella zoster virus in solid organ transplantation: guidelines from the American Society of Transplantation Infectious Diseases Community of Practice. Clin Transplant. 2019;33:e13622.

Publisher's Note Springer Nature remains neutral with regard to jurisdictional claims in published maps and institutional affiliations. 